\title{
Asparaginyl-tRNA synthetase gene (SYNC1) characterized by Lotus corniculatus FOX-superroot lines has effects on plant morphology and amino acid contents of seed in soybean
}

\author{
Azeri Gautama Arifin ${ }^{1, \dagger}$, Takahiro Gondo ${ }^{2, \dagger}$, Ryo Akashi ${ }^{1, *}$ \\ ${ }^{1}$ Faculty of Agriculture, University of Miyazaki, 1-1 Nishi Gakuen-kibanadai, Miyazaki 889-2192, Japan; ${ }^{2}$ Frontier Science \\ Research Center, University of Miyazaki, 1-1 Nishi Gakuen-kibanadai, Miyazaki 889-2192, Japan \\ *E-mail: rakashi@cc.miyazaki-u.ac.jp Tel: +81-985-58-7257 Fax: +81-985-58-7761
}

Received August 8, 2019; accepted October 16, 2019 (Edited by S. Nonaka)

\begin{abstract}
The application of useful genes from model plants to crops is an important step to verify its agricultural usefulness. SYNC1, an asparaginyl-tRNA synthetase gene, was previously identified through the Full-length cDNA OvereXpressor gene (FOX gene-hunting system) of Arabidopsis cDNA by using super-growing root (SR) culture of Lotus corniculatus, and was suggested to have a potential in increasing some amino acid contents and plant biomass. To identify the functionality of SYNC1 gene in a typical legume crop soybean, the effects of its overexpression in transgenic plants to agricultural traits and free amino acid contents were evaluated. The transgenic soybean plants were produced from infected half-seed explants of 1 day old seedlings with the suspension of Agrobacterium tumefaciens harboring expression vector pB7WG2D-SYNC1. The transgenic plants that overexpressed SYNC1 gene had increased asparagine and lysine contents in matured seeds, and increased aspartate, lysine, alanine and histidine contents in germinated seeds. The changes in those free amino acid contents affected plant morphology and led to significant increase in plant length, number of branches and number of branch nodes as yield components of soybean. The transgenic plants also showed a tendency of higher number of pods, seeds and total seed weight per plant. These results showed that the overexpression of SYNC1 gene contributes on the increase of plant free amino acid contents and biomass, and this approach is expected to be applicable in other legumes, grain and forage crops.
\end{abstract}

Key words: amino acid, FOX gene-hunting system, plant morphology, soybean, SYNC1.

\section{Introduction}

Legumes are the third largest and economically important family of flowering plants including food crops (e.g., soybean, peanuts, pea, chickpea, and lentil) and forage crops (e.g., alfalfa and clover). In the last century, the global population has been increasing along with competition for natural resources, which contributes to rising demand for overall crop production (Ortiz-Ospina et al. 2019). To meet demands, agriculture has to increase their production either through conventional or genetic modification. The recent development of genetic modification such as genetic transformation provides an opportunity to improve and modify plants for important traits. In order to modify the desirable traits, identification of candidate genes within a region of interest must be made by sequencing the whole genome. However, the whole genome sequencing has been advanced mainly on model plants. It will be important to identify the gene functions and apply the information into crops. Full-length cDNA OvereXpressor gene-hunting system (FOX gene-hunting system) is a powerful tool to analyze gene functions in plants by ectopically overexpressing full-length cDNA. It can generate large numbers of dominant mutations, thereby enabling the comprehensive characterization of novel and important traits and the identification of the causal genes (Ichikawa et al. 2006). In the previous study, Himuro et al. (2011) successfully applied the FOX hunting system on super-growing root (SR) of bird's foot trefoil (Lotus corniculatus) to generate 130 Arabidopsis FOX-superroot lines (FSL). These FSLs were produced by inserting Arabidopsis cDNA for functional analysis of genes expressed in SR. The SR is a fast-growing root culture that allows continuous root cloning and plant regeneration under hormone-free culture conditions (Akashi et al. 2000). Some of FSLs had interesting root characteristics compared to control, such as differences in color, growth rate, and size (Himuro et al. 2011).

SYNC1 gene (asparaginyl-tRNA aynthetase) was

${ }^{\dagger}$ These authors contributed equally to this work. This article can be found at http://www.jspcmb.jp/ Published online December 18, 2019 
found in FOX-SR lines (FSL\#) 121, introducing an Arabidopsis asparaginyl-tRNA synthetase, one of the genes in the family of aminoacyl-tRNA synthetases (aaRSs) class II (Himuro et al. 2011; Yano et al. 2014). Aminoacyl-tRNA synthetases are enzymes essential for translation of genetic transformation into protein gene products by attaching the appropriate amino acid onto its tRNA (Auborg et al. 1998). In most organisms, 20 aaRS, one for each specific amino acid, provide the various aminoacy-tRNA (aa-tRNA) for protein synthesis (Becker and Daniel 1998). Those aaRSs are required to be present in three cellular compartments of the plant, i.e., cytosol, mitochondria, and chloroplasts (Duchene et al. 2005). This FSL\#121 had an increase in major part of yield component, such as plant length, stem diameter, root length, root diameter, and nodule number compared to control. Furthermore, SYNC1 gene was found to lead an increase in the amount of amino acid in FSL\#121 (Yano et al. 2014). These results support that the over expression of the SYNC1 gene increases the plant biomass and improves the nutritional value of the seed in leguminous plants. This fundamental results are expected to be applied into legume crops.

In this study, we have developed transgenic soybean plants introduced with SYNC1 gene and evaluated the effect of SYNC1 gene overexpression to agricultural traits and free amino acid contents in seeds. The transgenic plants with SYNC1 gene showed a significant increase in plant height, number of branches, branch nodes, and number of seeds. Moreover, some free amino acid contents, such as asparagine, lysine, aspartate, alanine and histidine increased in transgenic soybean seeds. These results can be expected as the SYNC1 gene works to increase the crop yield and change the free amino acid component.

\section{Materials and methods}

\section{Vector construction and Agrobacterium strain}

The soybean SYNC1 gene (GenBank: AK286835.1) was isolated from full length cDNA clones (RAFL09-68-N14) which was provided by the National BioResource Project, University of Miyazaki, Japan. The open reading frame of SYNC1 gene (1704bp) was sub cloned into the pENTR/D-TOPO vector (Invitrogen). SYNC1 gene was inserted with pB7WG2D vector (VIB-Ghent University, Ghent, Belgium) subjected to the LR reaction using the Gateway ${ }^{\circledR}$ LR Clonase ${ }^{\circledR}$ Enzyme Mix kit (Invitrogen). The T-DNA region on the constructed vector pB7WG2D-SYNC1 (Figure 1) contained a SYNC1 gene under the control of the cauliflower mosaic virus (CMV) $35 \mathrm{~S}$ promoter, an enhanced green fluorescent protein gene (EGFP, a visible marker) under the control of rolD promoter and phosphinothricin acetyltransferase gene (bar, a selectable marker).

\section{Plant material and explant preparation}

Soybean (Glycine max L.) 'Williams 82' was used in this experiment. Mature soybean seeds were surface-sterilized by exposing to chlorine gas produced by mixed of $100 \mathrm{ml}$ sodium hypochlorite and $3.5 \mathrm{ml}$ of $12 \mathrm{~N} \mathrm{HCl}$ in a desiccator for $20 \mathrm{~h}$ (Di et al. 1996). The seeds were then soaked in sterile distilled water for $20 \mathrm{~h}$ in the dark at $27^{\circ} \mathrm{C}$. For isolation of the explants, excises were made longitudinally along the hilum to separate two cotyledons and the seed coat was removed. The two splitcotyledons then cut horizontally to makes it half-seed. The seeds with intact embryonic tip were used as explant.

\section{Agrobacterium infection}

Soybean transformation was performed by using Agrobacterium tumefaciens strain EHA105 harboring the binary vector pB7WG2D-SYNC1. For colony formation, the bacteria was grown on YEP solid media $\left(10 \mathrm{gl}^{-1}\right.$ peptone, $5 \mathrm{gl}^{-1} \mathrm{NaCl}$, $5 \mathrm{gl}^{-1}$ yeast extract, $\mathrm{pH} 7.0$, with $1.5 \%(\mathrm{w} / \mathrm{v})$ agar) containing $7.5 \mathrm{mgl}^{-1}$ spectinomycin, $1.25 \mathrm{mgl}^{-1}$ chloramphenicol, and $50 \mathrm{mgl}^{-1}$ rifampicin at $27^{\circ} \mathrm{C}$ in the dark for 3 days. A single bacterial colony was transferred to $10 \mathrm{ml}$ of liquid YEP medium with $7.5 \mathrm{mgl}^{-1}$ spectinomycin, $1.25 \mathrm{mgl}^{-1}$ chloramphenicol, and $50 \mathrm{mgl}^{-1}$ rifampicin overnight. The A. tumefaciens cells were then collected by centrifugation and re-suspend in liquid co-cultivation medium (CM) consisting of MS salts (Murashige and Skoog 1962), B5 vitamins (Gamborg et al. 1968), $30 \mathrm{gl}^{-1}$ sucrose, $4.27 \mathrm{gl}^{-1} \mathrm{MES}, 1.67 \mathrm{mgl}^{-1} \mathrm{BAP}, 3.3 \mathrm{mM}$ cysteine, $0.25 \mathrm{mgl}^{-1} \mathrm{GA} 3,0.2 \mathrm{mM}$ acetosyringone, and $1.0 \mathrm{mM}$ dithiothrietol, with $\mathrm{pH}$ 5.4. The cell density was adjusted to OD650 of 0.6 to 0.8 using a spectrophotometer and the suspensions were added with $0.02 \%(\mathrm{w} / \mathrm{v})$ of silwet77 (Lehle Seeds, Round Rock, TX) before infection.

The infection of half-seed explants were done by brushing the suspension of A. tumefaciens several times at the nodal area of cotyledon and incubated with Agrobacterium for $30 \mathrm{~min}$ at

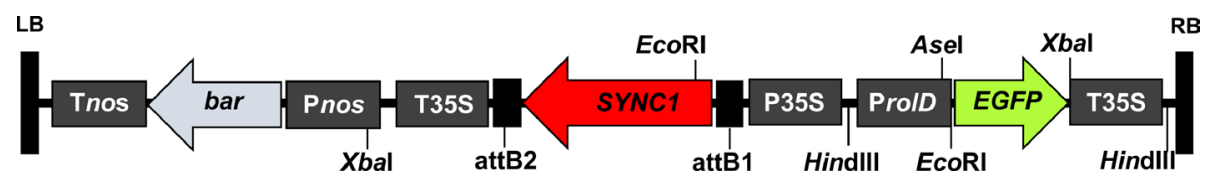

Figure 1. Schematic representation of T-DNA regions of p7WG2D-SYNC1 (12.6 Kbp). Abbreviations: Tnos (nopaline synthase terminator), bar (phosphinothricin $N$-acetyltransferase gene), Pnos (nopaline synthase promoter), XbaI (Xanthomonas badrii restriction enzymes), T35S (35S terminator), P35S (35S promoter), attB1 and attB2 (recombination sites), SYNC1 (soybean asparaginyl-tRNA synthetase gene), EcoRI (E. coli restriction enzymes), HindIII (Haemophilus influenza restriction enzymes), ProlD (rolD promoter), AseI (Aquaspirillum serpens restriction enzymes), EGFP (enchanced green fluorescent protein gene), LB and RB (left and right border). 
$27^{\circ} \mathrm{C}$ in the dark. After the incubation, the explants were placed adaxial side facing down on solid CM medium $(0.5 \%(\mathrm{w} / \mathrm{v})$ agar) lined with filter paper and co-cultivated at $27^{\circ} \mathrm{C}$ in the dark for 5 days.

\section{Selection and regeneration of transgenic plants}

The shoot induction of explants began after 5 days of cocultivation. Before moving to shoot induction (SI) medium, explants were washed in sterile distilled water containing $25 \mathrm{mgl}^{-1}$ Meropen $^{\circledR}$ (Dai Nippon Sumitomo Pharma) and blotted on sterile filter paper. SI medium consisted of MS salts, B5 vitamins $30 \mathrm{gl}^{-1}$ sucrose, $0.64 \mathrm{gl}^{-1} \mathrm{MES}, 1.67 \mathrm{mgl}^{-1} \mathrm{BAP}$, and $25 \mathrm{mgl}^{-1}$ Meropen $^{\circledR}$, with $\mathrm{pH}$ 5.7, and solidified with $0.7 \%$ (w/v) agar. After 2 weeks, the explants were transferred to fresh SI medium with the addition of $6 \mathrm{mgl}^{-1}$ bialaphos. The early developing shoots were removed by a surgical scalpel during shoot induction. After a total of 4 weeks of culture in SI medium, the explants were transferred to shoot elongation (SE) medium (MS salts, B5 vitamins, $30 \mathrm{gl}^{-1}$ sucrose, $0.64 \mathrm{gl}^{-1}$ MES, $1.67 \mathrm{mgl}^{-1}$ BAP, $25 \mathrm{mgl}^{-1}$ Meropen $^{\circledR}, 6 \mathrm{mgl}^{-1}$ bialaphos, $1 \mathrm{mgl}^{-1}$ zeatin riboside, $0.25 \mathrm{mgl}^{-1} \mathrm{GA} 3,0.1 \mathrm{mgl}^{-1}$ IAA, $100 \mathrm{mgl}^{-1}$ glutamic acid, and $100 \mathrm{mgl}^{-1}$ asparagine, with $\mathrm{pH} 5.7$, solidified with $0.7 \%(\mathrm{w} / \mathrm{v})$ agar) and were sub-cultured every 2 weeks onto the same medium. During the shoot elongation culture, the presence of transgenic shoots was confirmed by observation of green fluorescent protein (GFP) fluorescence under the blue light and yellow filter (excitation 460-490 nm, emission $510 \mathrm{~nm}$ ). Elongating transgenic shoots with over $2 \mathrm{~cm}$ and emitting GFP fluorescence were obtained and were dipped in $1 \mathrm{mgl}^{-1}$ indole butyric acid then transferred to rooting medium (MS salts, B5 vitamins, $20 \mathrm{gl}^{-1}$ sucrose, $0.64 \mathrm{gl}^{-1} \mathrm{MES}$, and $25 \mathrm{mgl}^{-1}$ Meropen $^{\circledR}$, with $\mathrm{pH}$ 5.7, solidified with $0.7 \%$ (w/v) agar). After 2 weeks, rooted plantlets were transplanted to soil in pots. The $\mathrm{T}_{0}$ plants were grown in a growth chamber at $27^{\circ} \mathrm{C}$ with $16 / 8 \mathrm{~h}$ light/dark regime.

The $\mathrm{T}_{0}$ plants were cultivated to the $\mathrm{T}_{3}$ generation, and its GFP expression were confirmed in the seeds for every generation to achieve homozygous transgenes. Southern blot analysis and PCR were performed in $\mathrm{T}_{0}$ and $\mathrm{T}_{1}$ generations, respectively, to analyze the segregation of transgenes. Moreover, qRT-PCR, plant morphology and free amino acid content were analyzed in the $\mathrm{T}_{3}$ generation of transgenes homozygous lines.

\section{Southern blot analysis in $T_{0}$ and $P C R$ in $T_{1}$ generation}

The confirmation of transgene insertion in $\mathrm{T}_{0}$ plants was done by using Southern blot analysis. Total genomic DNA was extracted from $1.2 \mathrm{~g}$ wild type and putative transgenic soybean leaves following the CTAB protocol (Doyle and Doyle 1990). Fifteen $\mu \mathrm{g}$ of genomic DNA digested with AseI was separated on $0.8 \%$ agarose gel and transferred to Hybond ${ }^{\circledR}$ nylon membranes (Roch, Germany). Membranes were hybridized using a 485 bp EGFP gene fragment labeled with a PCR DIG probe synthesis kit (Roch, Germany). Hybridization signals were visualized on FUJI X-ray film (Fuji, Japan).
PCR analysis was performed to confirm transgene segregation in the $T_{1}$ generation. The genomic DNA was extracted from leaf tissue of putative transgenic soybean using DNeasy Plant Mini Kit (QIAGEN, Hilden, Germany). SYNC1 gene was amplified by PCR using primers (forward/ reverse) 5' -GCC AAG TAT CCT CTG CCC AAA ATG-3' ' $5^{\prime}$ CCC TTT GGC TTC CAC CAA TTA GC- $3^{\prime}$. The condition for PCR of SYNC1 gene were $10 \mathrm{~min}$ at $95^{\circ} \mathrm{C}$ for preheating and followed by 35 cycles of $30 \mathrm{~s}$ at $95^{\circ} \mathrm{C}$ for denaturation, $60 \mathrm{~s}$ at $68^{\circ} \mathrm{C}$ for annealing and elongation. Samples were then subjected to an additional $7 \mathrm{~min}$ at $72^{\circ} \mathrm{C}$ and stored in $4^{\circ} \mathrm{C}$. PCR products were separated by $1.5 \%$ agarose gel electrophoresis.

\section{Quantitative Reverse transcriptase-PCR (qRT-PCR)}

Total RNA was extracted from $\mathrm{T}_{3}$ generation transgenic $\mathrm{L} 3$ line leaves using RNeasy ${ }^{\circledR}$ Plant Mini Kit (Qiagen, Netherlands) following the manufacturer's instructions. Extracted total RNA was reverse transcribed using QuantiTect ${ }^{\circledR}$ Reverse Transcription Kit. The qRT-PCR analysis was performed by using Applied Biosystem Veriti ${ }^{\mathrm{TM}} 96$ Well Thermal Cycler. Each reaction contained $5 \mu \mathrm{l}$ of synthesized cDNA, $1 \mu \mathrm{l}$ gene specific primers, $10 \mu \mathrm{l}$ Power SYBR $^{\circledR}$ Green PCR Master Mix, and $3 \mu \mathrm{l}$ Nuclease-free water. Primers for SYNC1 were 5' -CAT CTG AGC ATG AAA GAT ACC TAA C-3' and 5' GAT GTG CTT GTA CCC AAGGT-3' primers, for ACTIN1 gene (NCBI XM-003552652.1) as a reference gene were 5' - ATC TTG ACT GAG CGT GGT TAT TCC-3' and 5' GGA GAC AGCCAG GACCAGC-3' (Hu et al. 2009). The PCR conditions for the investigation of SYNC1 and ACTIN1 gene expression were as follows: $10 \mathrm{~min}$ at $95^{\circ} \mathrm{C}$ for denaturation, followed by 40 cycles of $15 \mathrm{~s}$ at $95^{\circ} \mathrm{C}$ for denaturation, $30 \mathrm{~s}$ at $60^{\circ} \mathrm{C}$ for annealing and $1 \mathrm{~min}$ at $72^{\circ} \mathrm{C}$ for elongation. Four biological replications with five technical replications per a biological replication were applied for the experiment. The data were analyzed using the comparative $\Delta \Delta \mathrm{Ct}$ method.

\section{Characteristics of transgenic plants}

$\mathrm{T}_{3}$ generation transgenic L3 line and wild type were sown three seeds per $1 / 5000$ a pot containing sterile soil (Miyazaki Shodo) in the greenhouse at the University of Miyazaki, Japan. After 7 days of sowing, germinated seeds were selected one plant per pot and the plants were cut at between fifth and sixth major leaf in 40 days of cultivation. Investigations of nine agronomic traits were summarized in Table 1. Plant length was measured on the first month, and leaf length, leaf width, number of branch, branch node and pods were measured on the fourth month of cultivation. After harvesting the seeds, number of seeds, seed weight per plant, and 1,000 seeds weight were measured. In this experiment, there are seven plants that had been cultivated from each line. Only five grown plants with average value that used for statistical analysis.

\section{Measurement of free amino acid content}

Mature and germinated seeds of $\mathrm{T}_{3}$ generation transgenic line (L3) and WT were used for free amino acid analysis. 

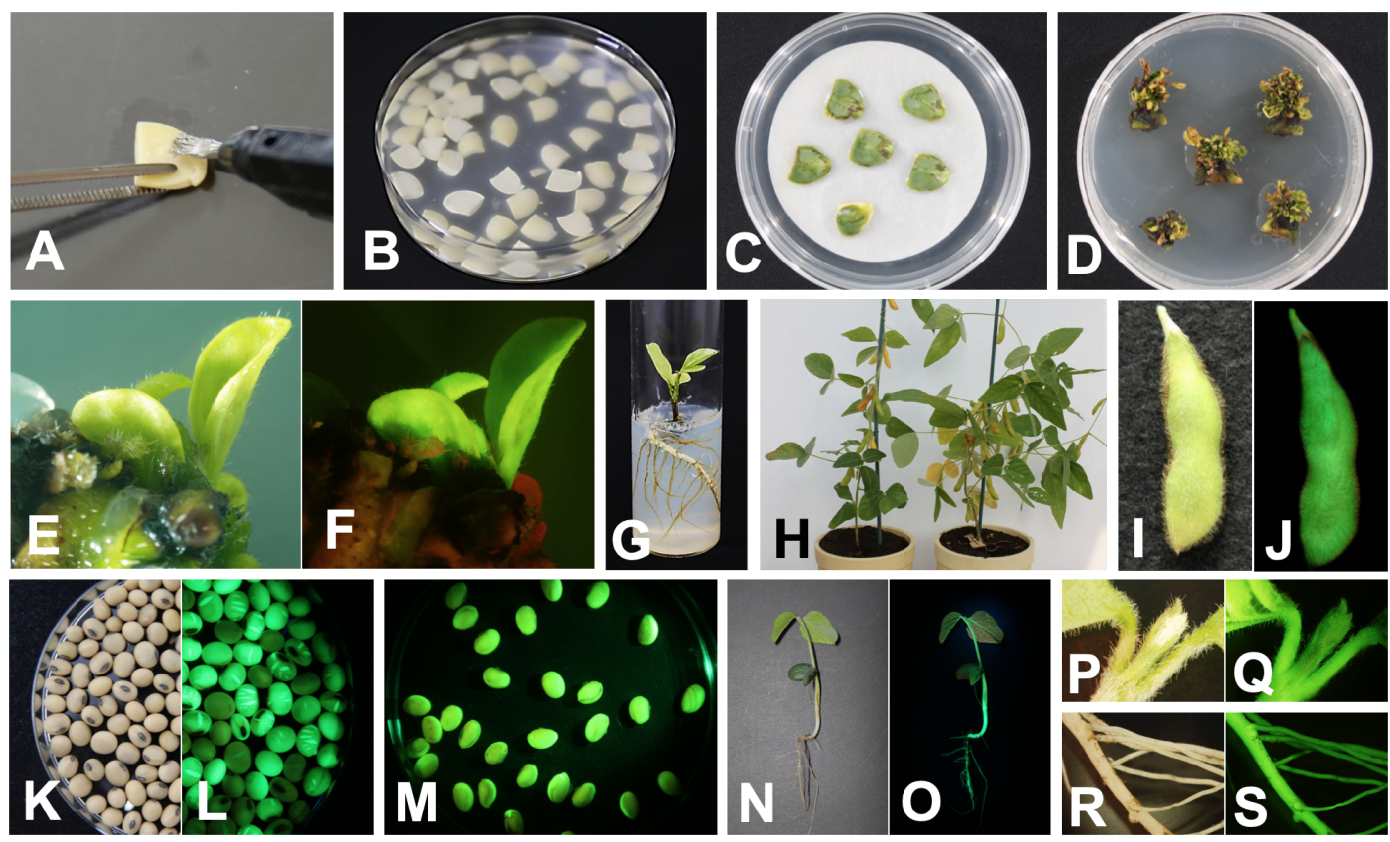

Figure 2. Agrobacterium-mediated transformation and GFP expression in transgenic soybean. (A) Wounding of half-seed explant by using a micro-brush; (B) Inoculation with Agrobacterium in liquid co-cultivation media (CM); (C) Co-cultivation of half-seed explants with Agrobacterium on solid CM medium lined with filter paper; (D) Four weeks after selection on shoot induction medium containing $6 \mathrm{mgl}^{-1}$ bialaphos; (E, F) Stable GFP expression during the shoot induction selection stage (F under fluorescent); (G) Rooting of putative transgenic plant; (H) Wild type (left) and $\mathrm{T}_{0}$ transgenic plant (right) in greenhouse; (I, J) Stable GFP expression of silique pod (J under fluorescent); (K, L) GFP expression on heterozygous $\mathrm{T}_{2}$ seeds ( $\mathrm{L}$ under fluorescent); $(\mathrm{M})$ homozygous $\mathrm{T}_{2}$ transgenic soybean seeds under fluorescent; $(\mathrm{N}, \mathrm{O}, \mathrm{P}, \mathrm{Q}, \mathrm{R}, \mathrm{S})$ Stable GFP expression of $\mathrm{T}_{3}$ transgenic plant (O, Q, S under fluorescent).

Germinated seeds were produced by soaking the sterile seeds in $25 \mathrm{ml}$ sterile distilled water per a $90 \mathrm{~mm}$ Petri dish and incubated at $27^{\circ} \mathrm{C}$ in the dark for 2 days. Powdered samples $(150 \mathrm{mg}$ ) were homogenized with $400 \mu \mathrm{l}$ of $15 \mathrm{mM} \mathrm{HCl}$ then centrifuged at 20,000 rpm for 2 min to transfer the supernatant. Proteins of the supernatant were removed by the addition of $30 \mu \mathrm{l}$ of $10 \%$ sulfosalicylic acid followed by keeping on ice for $15 \mathrm{~min}$ and centrifugation at $20,000 \mathrm{rpm}$ for $15 \mathrm{~min}$ at $4^{\circ} \mathrm{C}$. The supernatants were adjusted with $2 \mathrm{~N} \mathrm{NaOH}$ to $\mathrm{pH}$ 6-8 and used to measure the free amino acid contents. The mixture of $50 \mu \mathrm{l}$ filtered samples, $100 \mu \mathrm{l}$ acetonitrile, and $50 \mu \mathrm{l}$ internal standard solution were then analyzed with a UF-Amino Station (Shimadzu, Kyoto, Japan).

\section{Results}

\section{Transformation of soybean}

The transgenic soybean plants were produced from infected half-seed explants with the suspension of $A$. tumefaciens harboring the expression vector pB7WG2DSYNC1 (Figure 1). Explants were wounded by using a micro-brush (Figure 2A) and incubated in CM liquid medium with Agrobacterium at $27^{\circ} \mathrm{C}$ for $30 \mathrm{~min}$ in the dark (Figure 2B). Explants were co-cultivated on $\mathrm{CM}$ solid medium lined with filter paper for 5 days (Figure 2C) followed by shoot induction for 14 days in SI medium. The inducted shoots were cut and the explants transferred onto the SI medium supplemented with

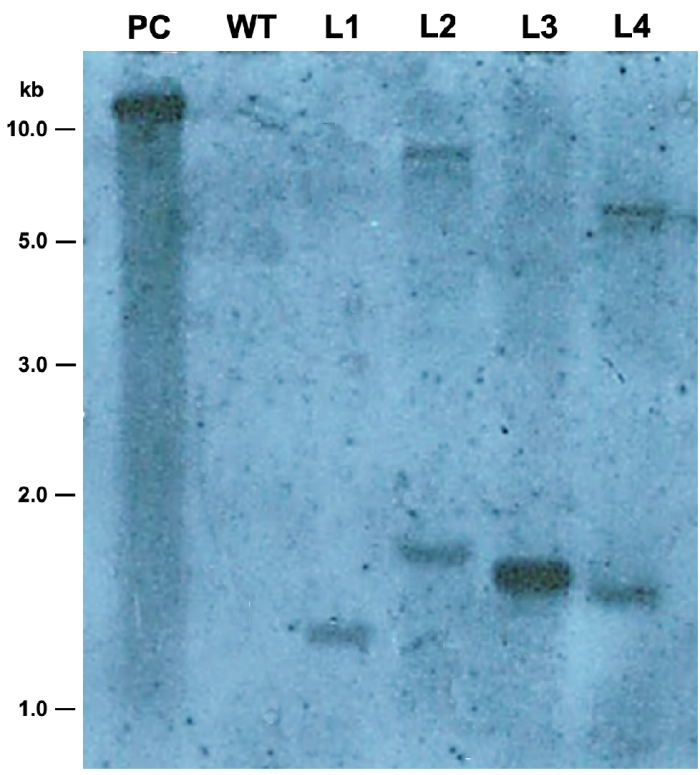

Figure 3. Analysis of putative transgenic soybean plant by DNA gel blot analysis. Fifteen (15) micrograms genomic DNA isolated from leaf tissue of non-transgenic wild type (WT) and four independent putative transgenic lines (L1-4) were digested with AseI. Hybridization was carried out with a DIG-dUTP labeled EGFP gene probe. PC is positive control of 5 pg AseI-digested pB7WG2D-SYNC1 plasmid DNA.

$6 \mathrm{mgl}^{-1}$ bialaphos. Almost explants gradually turned brown, but bialaphos resistant shoots were identified after 14 days of culture. The bialaphos-resistant shoots 
(Figure 2D) were elongated in SE medium for 30 days. These shoots indicated with a stable GFP expression (Figure 2E, F) were then transferred to the rooting medium (Figure 2G). After the roots of putative transgenic plants were fully developed to $3-4 \mathrm{~cm}$ in length, plantlets were eventually transplanted in the soil and grown in a growth-chamber with $16 / 8 \mathrm{~h} \mathrm{light/dark}$ condition (Figure $2 \mathrm{H}$ ). These plants set the pods (Figure 2I, J) and produced the seeds.

\section{Analysis of putative transformants}

The presence of EGFP gene in genomic DNA of four independent putative transgenic lines of soybean was confirmed by DNA gel blot hybridization (Figure 3). The genomic DNA restricted by AseI with a single cutting site in T-DNA region was hybridized with EGFP gene fragments probe. The result showed that the putative transgenic plants had single or double bands of EGFP gene. L3 line had single and clear hybridized band, while the other lines showed unclear and weak bands.

The PCR analysis in $\mathrm{T}_{1}$ plants were performed in $\mathrm{L} 1$, L3, and L4 lines except for L2 line which failed to grow into the reproductive stage to produce seeds (Figure 4). The PCR analysis was run to all lines of $\mathrm{T}_{1}$ to identify endogenous genomic SYNC1 gene. All lines showed the same endogenously derived genomic SYNC1 bands as wild type, except L3 line that showed introduced SYNC1 cDNA band. This result means that introduced SYNC1 gene was inherited to the next generation only in L3 line.

\section{Homozygous transgene and GFP expression}

To obtain homozygous transgenic lines, self-pollination and selection based on GFP expression were performed in L3 transgenic line. The seeds that expressed GFP were segregated in $\mathrm{T}_{2}$ generation (Figure $2 \mathrm{~K}, \mathrm{~L}$ ) and the homozygous transgene was confirmed in $\mathrm{T}_{3}$ generation (Figure 2M). Figure 2N-S showed GFP expression in L3 transgenic line of $\mathrm{T}_{3}$ generation, a stable GFP expression was indicated under florescent within the whole plant. In the following experiments, $\mathrm{T}_{3}$ generations of $\mathrm{L} 3$ transgenic line were used.

\section{Effect of overexpression of SYNC1 gene in agronomic traits}

The expression of SYNC1 gene was confirmed in $\mathrm{T}_{3}$ generation of L3 transgenic line by qRT-PCR. L3 line showed high expression of SYNC1 gene and the expression level indicated 4.8 times higher than that of wild type (Figure 5). Subsequently, to evaluate the effect of SYNC1 gene overexpression in agronomic traits of transgenic soybean, morphology of L3 line and wild type were compared (Table 1). The L3 line significantly increased in plant length, number of branches, and number of branch nodes than the wild type. Moreover, the transgenic L3 line showed a tendency of higher

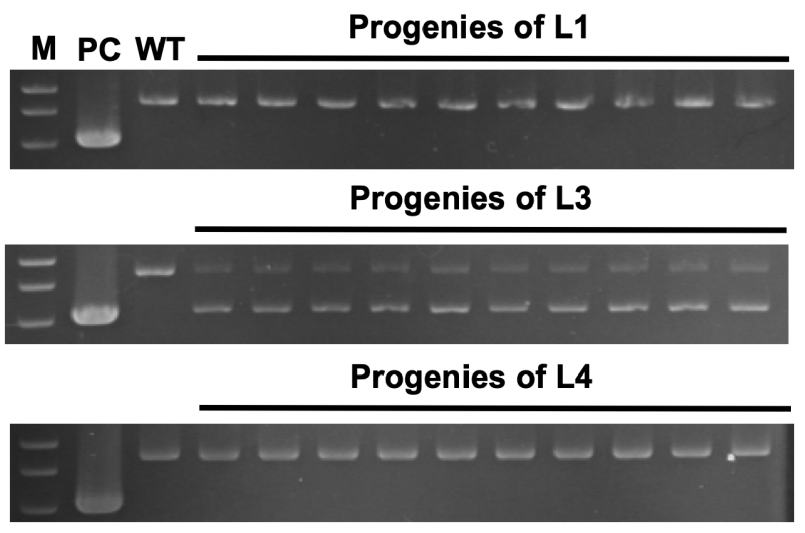

Figure 4. PCR analysis of progenies of putative transgenic lines (L1, L3, L4). M: 1 kbp ladder, PC: plasmid DNA pB7WG2D-SYNC1, WT: non-transgenic wild type soybean.

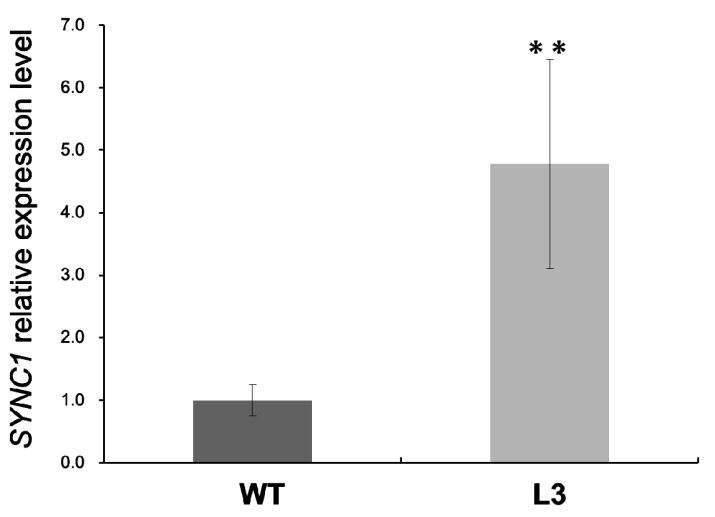

Figure 5. Expression of SYNC1 gene in leaf tissue of wild type soybean and positive $\mathrm{T}_{3}$ generation of $\mathrm{L} 3$ transgenic line by quantitative RT-PCR. The expression data represent the mean \pm SD of four independent plants, with each plant having five technical replicates. ** represent significant differences at $p<0.01$ between the transgenic line $\mathrm{L} 3$ and the WT.

Table 1. Comparison of agronomic traits in wild type (WT) and L3 transgenic soybean line.

\begin{tabular}{lcc}
\hline \multicolumn{1}{c}{ Trait } & WT & L3 \\
\hline Plant length $(\mathrm{cm})$ & $54.2 \pm 33.0$ & $107.3 \pm 5.9^{* *}$ \\
Leaflet length $(\mathrm{mm})$ & $78.3 \pm 6.8^{*}$ & $68.5 \pm 4.3$ \\
Leaflet width $(\mathrm{mm})$ & $58.2 \pm 9.0^{*}$ & $47.8 \pm 4.3$ \\
Number of branches & $1.8 \pm 0.5$ & $3.8 \pm 1.1^{*}$ \\
Number of branch nodes & $11.8 \pm 1.8$ & $20.0 \pm 6.6^{*}$ \\
Number of siliques per plant & $13.3 \pm 2.6$ & $16.0 \pm 5.7$ \\
Number of seeds per plant & $23.2 \pm 7.5$ & $29.2 \pm 9.2$ \\
Seed weight per plant $(\mathrm{g})$ & $3.3 \pm 1.0$ & $3.5 \pm 1.1$ \\
Mass of 1,000 seeds $(\mathrm{g})$ & $138.9 \pm 15.0^{*}$ & $116.0 \pm 4.3$
\end{tabular}

The trait data represent the mean \pm standard deviation of five independent plants. $*$ and $* *$ represent significant difference at $p<0.05$ and $<0.01$ between the transgenic lines L3 and the WT, respectively.

number of pods, seeds, and total seed weight per plant. However, the number of transgenic leaflet length, leaf width, and mass of 1,000 seeds were lower than that of the wild type. Figure 6 showed that transgenic plant 

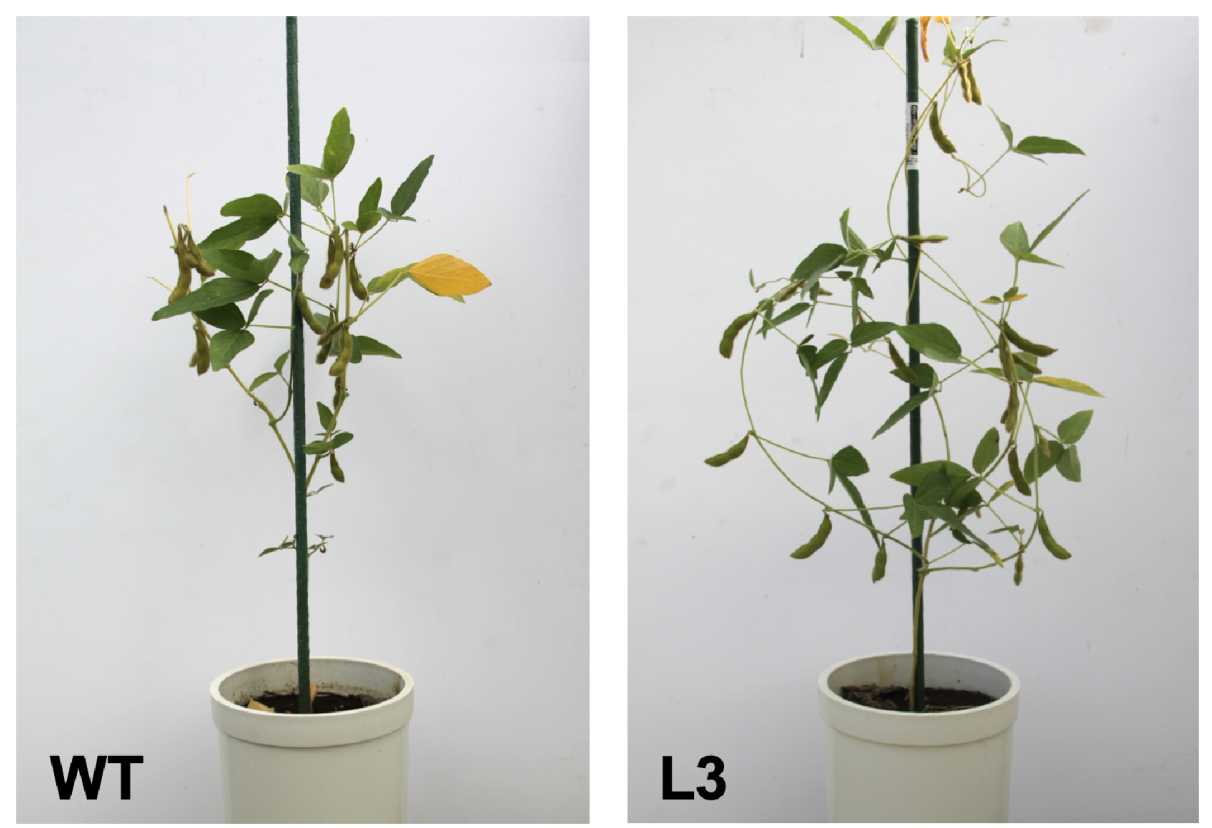

Figure 6. Phenotype of wild type soybean and $\mathrm{T}_{3}$ generation of $\mathrm{L} 3$ transgenic line in 100 days after germination. Pot size was $17.5 \mathrm{~cm}$ in diameter.

was bigger than wild type which is supported by the morphology data (Table 1).

\section{Free amino acid contents of transgenic plants}

To determine the effect of overexpressed SYNC1 gene on amino acid contents in soybean seed, free amino acid was measured in both matured seeds and germinated seeds. There were 19 free amino acids analyzed as shown in Table 2. Some of those free amino acids were affected by the overexpression of SYNC1 gene, especially oxaloacetate acid group. L3 transgenic line indicated that lysine contents in both type of seeds were significantly higher than those in wild type. Asparagine content in matured seeds of L3 line was about twice higher than that in the wild type. Although aspartate contents in matured seed of L3 line was lower compared to that of the wild type, the opposite result was found in germinated seeds of L3 line. The total content of oxaloacetate in germinated seeds of L3 line was higher than in wild type. The other free amino acid contents, alanine and histidine, were significantly high in germinated seeds of L3 line. In addition, the total free amino acid contents increased in both type of seeds of L3 line.

\section{Discussion}

The putative transgenic soybean plants were produced from in vitro culture of half-seed explants infected with Agrobacterium harboring binary vector pB7WG2DSYNC1. Four lines of putative transgenic plants were produced, but the transformation efficiency was lower than the previous reports ( $\mathrm{Paz}$ et al. 2006; Song et al. 2013). Furthermore, only one transgenic line (L3 line) transmitted to $T_{1}$ generation, while other lines failed to inherit the transgene to the next generation (Figure 4). The lines that did not inherit the transgene in $\mathrm{T}_{1}$ generation were later found out to be caused by chimerism, which was developed by mixed transformed and untransformed cells in the same individual. Despite many reports that indicated that half-seed explants were the most suitable (Kim et al. 2012; Meurer et al. 1998; Paz et al. 2006) and offer faster regeneration of fertile soybean plants and which does not require the maintenance of parental donor plants (Meurer et al. 1998), this system still has a major problem of chimerism and low transformation efficiency such as in this study. Embryonic tip is useful explant for transformation because its meristem has strong ability for cell division (Jimenez 2001). Apical meristems are target for transformation because this region is the basal position of cell division and differentiation. This transformation system is suggested to have higher transformation efficiency and could solve the chimerism problem. Therefore, we consider that embryonic tip transformation system has more advantages over half seed transformation method.

To produce functional RNA as the final product of gene expression, the information from a gene have to go through transcription and translation. While doing translation, ribosome will polymerizing conjugation of amino acid and tRNA into protein. To conjugate appropriate amino acid to its tRNA, tRNA ligase such as aminoacyl-tRNA synthetase (aaRS) is needed. SYNC1 is a gene that encodes asparaginyl-tRNA synthetase, which is essential for the production of asparaginyltRNA in translation (Peeters et al. 2000). Asparaginyl- 
Table 2. Free amino acids contents in soybean seeds of wild type (WT) and L3 transgenic line

\begin{tabular}{|c|c|c|c|c|}
\hline \multirow{2}{*}{$\begin{array}{c}\text { Amino Acid } \\
\left(\mu \mathrm{g} \mathrm{g}^{-1} \text { Fresh Weight }(\mathrm{FW})\right)\end{array}$} & \multicolumn{2}{|c|}{ Matured seed } & \multicolumn{2}{|c|}{ Germinated seed } \\
\hline & WT & L3 & WT & L3 \\
\hline \multicolumn{5}{|l|}{ Oxaloacetate acid group } \\
\hline Aspartate & $735.5 \pm 54.5^{*}$ & $527.6 \pm 112.3$ & $53.3 \pm 5.3$ & $77.2 \pm 12.7 *$ \\
\hline Asparagine & $101.9 \pm 14.2$ & $241.7 \pm 62.8^{*}$ & $86.7 \pm 13.0$ & $126.0 \pm 30.0$ \\
\hline Threonine & $3.6 \pm 2.1$ & $11.7 \pm 8.3$ & $93.7 \pm 17.7$ & $106.0 \pm 5.6$ \\
\hline Isoleucine & $66.8 \pm 14.3$ & $75.7 \pm 5.5$ & $114.1 \pm 13.0$ & $113.1 \pm 16.0$ \\
\hline Methionine & $15.9 \pm 3.4$ & $20.8 \pm 2.8$ & $40.3 \pm 7.0$ & $48.4 \pm 5.1$ \\
\hline Lysine & $72.0 \pm 12.6$ & $106.1 \pm 18.3^{*}$ & $193.9 \pm 16.3$ & $238.0 \pm 13.7^{*}$ \\
\hline (Total) & $995.7 \pm 98.3$ & $983.6 \pm 98.8$ & $582.0 \pm 59.0$ & $708.7 \pm 50.3^{*}$ \\
\hline \multicolumn{5}{|l|}{ Pyruvic acid group } \\
\hline Alanine & $79.8 \pm 7.0$ & $240.2 \pm 127.3$ & $261.8 \pm 62.7$ & $424.6 \pm 89.2 *$ \\
\hline Leucine & $34.0 \pm 9.5$ & $41.5 \pm 6.1$ & $151.1 \pm 20.2$ & $180.9 \pm 16.0$ \\
\hline Valine & $45.6 \pm 10.2$ & $61.7 \pm 12.2$ & $120.1 \pm 14.5$ & $131.2 \pm 8.0$ \\
\hline (Total) & $159.4 \pm 24$ & $343.4 \pm 140.0$ & $533.0 \pm 95.2$ & $736.7 \pm 107.1^{*}$ \\
\hline \multicolumn{5}{|l|}{$\alpha$-ketoglutaric acid group } \\
\hline Glutamic acid & $358.4 \pm 49.7$ & $477.6 \pm 200.9$ & $60.3 \pm 28.7$ & $87.5 \pm 25.1$ \\
\hline Glutamine & $9.7 \pm 3.2$ & $17.3 \pm 4.7$ & $70.0 \pm 2.9$ & $96.1 \pm 17.8$ \\
\hline Proline & $36.2 \pm 8.9$ & $65.6 \pm 21.6$ & $122.6 \pm 10.6$ & $109.7 \pm 15.8$ \\
\hline Arginine & $769.3 \pm 181.4$ & $1122.3 \pm 273.0$ & $399.8 \pm 83.5$ & $524.7 \pm 74.0$ \\
\hline (Total) & $1173.6 \pm 150.1$ & $1682.8 \pm 482.0$ & $652.6 \pm 115.7$ & $818.0 \pm 81.5$ \\
\hline \multicolumn{5}{|l|}{ Phosphoenol pyruvic acid } \\
\hline Tryptophan & $68.6 \pm 4.2$ & $56.0 \pm 44.6$ & $76.1 \pm 9.8$ & $66.5 \pm 19.5$ \\
\hline Tyrosine & $27.3 \pm 9.5$ & $62.2 \pm 32.8$ & $202.1 \pm 26.6$ & $238.0 \pm 24.2$ \\
\hline Phenylalanine & $57.3 \pm 17.5$ & $71.6 \pm 14.9$ & $155.0 \pm 14.3$ & $156.5 \pm 23.8$ \\
\hline (Total) & $153.3 \pm 37.1$ & $189.7 \pm 60.3$ & $433.2 \pm 33.6$ & $461.0 \pm 63.2$ \\
\hline \multicolumn{5}{|l|}{ 3-Phosphoglycerate acid group } \\
\hline Serine & $21.6 \pm 2.9$ & $26.7 \pm 6.9$ & $121.9 \pm 8.0$ & $129.0 \pm 20.7$ \\
\hline Glycine & $27.3 \pm 2.2$ & $50.6 \pm 20.0$ & $73.3 \pm 23.1$ & $64.8 \pm 7.4$ \\
\hline (Total) & $48.9 \pm 5.1$ & $77.2 \pm 26.9$ & $195.2 \pm 23.3$ & $193.8 \pm 14.4$ \\
\hline \multicolumn{5}{|l|}{ PRPP-derived } \\
\hline Histidine & $30.6 \pm 3.1$ & $43.4 \pm 10.1$ & $64.5 \pm 6.1$ & $79.8 \pm 7.9^{*}$ \\
\hline Total amount & $2502.4 \pm 296.6$ & $3242.9 \pm 684.1$ & $2265.3 \pm 232.0$ & $2804.1 \pm 240.7 *$ \\
\hline
\end{tabular}

tRNA synthetase precisely match asparagine with tRNA containing comparable anticodon (Ibba and Soll 2000). Thus, the overexpression of SYNC1 was considered to affect amino acid contents. To investigate the effect of SYNC1 gene in amino acid contents of transgenic soybean, both matured seeds and germinated seeds of $\mathrm{T}_{3}$ transgenic line were analyzed. The matured and germinated seeds were chosen because they are used as livestock feed and processed food, respectively. The introduction of SYNC1 into soybean in this experiment did not only increased asparagine content, but also aspartate and lysine, which are located downstream in the biosynthetic pathway of oxaloacetate acid group (Table 2). The transgenic L3 matured seeds was found with higher asparagine and lysine contents compared to the wild type. In addition, germinated seeds of transgenic L3 had higher contents of aspartate, lysine, alanine, and histidine compared to its wild type. These results support the hypothesis that overexpression of SYNC1 affect amino acid contents in plant. The similar result also found in the previous reports of aaRS overexpression such as asparaginyl-tRNA synthetase (SYNC1) overexpression in Lotus corniculatus (Yano et al. 2014) and lysyl-tRNA synthetase (AtKRS) overexpression in Zea mays (Wu et al. 2007).

Of the five amino acids that increased in L3 transgenic soybean, lysine and histidine are essential in farm animal and human diets. Lysine, in particular is limited in most grains, which made it necessary to be supplemented from legume crops to gain sufficient lysine intake. The increase of lysine content from the overexpression of SYNC1 gene was $47.4 \%$ and $22.7 \%$ in matured and germinated seed, respectively. Our results are higher than the per cent increase of lysine content in maize with overexpressed lysyl-tRNA synthetase (Wu et al. 2007). Instead of overexpressing lysyl-tRNA synthetase to increase lysine content, the overexpression of SYNC1 gene could increase lysine content more effectively. This approach 
was applicable in increasing lysine content as well as other amino acid contents.

The changes in asparagine and other amino acid contents of transgenic L3 line by overexpressing SYNC1 led changes on its morphological traits (Table 1). Plant length, number of branches and number of branch nodes in transgenic L3 line was higher than in wild type. However, its mass of 1,000 seeds, leaflet length and leaflet width were lower than wild type. Asparagine is an important nitrogen transport amino acid, and its efficient use in plant growth and development affects the amount of biomass and plant productivity (Gaufichon et al. 2016). The high growth of L3 line in this study was mainly due to high asparagine content in plant. This result was similar with the previous study in Lotus corniculatus overexpressed SYNC1 gene (Yano et al. 2014). Figure 6 shown a higher biomass in L3 line than that in wild type with the increase number of branches and branch nodes as yield component. Although the seed weight in L3 transgenic line decreased because of its small seed size, the number of seeds per plant were increased, which conduce to the increase of total seed yield.

In conclusion, overexpression of SYNC1 gene was effective to increase some free amino acid contents such as asparagine and lysine, which also have a possibility to increase plant biomass in soybean. Such synergy effects was an important discovery and have not been reported on another aaRS genes before. This approach is expected to be applied to increase the yield and improve the total free amino acid of another legume crops, grain, forage plants for animal feed and human diet.

\section{References}

Akashi R, Harris S, Hoffmann-Tsay S-S, Hoffmann F (2000) Plants from protoplasts isolated form a long-term root culture (Super Root) of Lotus corniculatus. J Plant Physiol 157: 215-221

Auborg S, Chéron A, Kreis M, Lecharny A (1998) Structure and expression of an asparaginyl-tRNA synthetase gene located on chromosome IV of Arabidopsis thaliana and adjacent to a novel gene of 15 exons. Bioenergetics 1398: 225-231

Becker HD, Kern D (1998) Thermus thermophilus: A link in evolution of the tRNA-dependent amino acid amidation pathways. Proc Natl Acad Sci USA 95: 12832-12837

Di R, Purcell V, Collins GB, Ghabrial SA (1996) Production of transgenic soybean lines expressing the bean pod mottle virus coat protein precursor gene. Plant Cell Rep 15: 746-750

Doyle JJ, Doyle JL (1990) Isolation of plant DNA from fresh tissue. Focus 12: 13-15

Duchêne A-M, Giritch A, Hoffmann B, Cognat V, Lancelin D, Peeters NM, Zaepfel M, Maréchal-Drouard L, Small ID (2005) Dual targeting is the rule for organellar aminoacyl-tRNA synthetases in Arabidopsis thaliana. Proc Natl Acad Sci USA 102: 16484-16489

Gamborg OL, Miller RA, Ojima K (1968) Nutrient requirements of suspension cultures of soybean root cells. Exp Cell Res 50: $151-158$

Gaufichon L, Rothstein SJ, Suzuki A (2016) Asparagine metabolic pathways in Arabidopsis. Plant Cell Physiol 57: 675-689

Himuro Y, Tanaka H, Hashiguchi M, Ichikawa T, Nakazawa M, Seki M, Fujita M, Shinozaki K, Matsui M, Akashi R, et al. (2011) FOX-superroots of Lotus corniculatus, overexpressing Arabidopsis full-length cDNA, show stable variations in morphological traits. J Plant Physiol 168: 18-187

Hu R, Fan C, Li H, Zhang Q, Fu Y-F (2009) Evaluation of putative reference genes for gene expression normalization in soybean by quantitative real-time RT-PCR. BMC Mol Biol 10: 93

Ibba M, Söll D (2000) Aminoacyl-tRNA synthesis. Annu Rev Biochem 69: 617-650

Ichikawa T, Nakazawa M, Kawashima M, Iizumi H, Kuroda H, Kondou Y, Tsuhara Y, Suzuki K, Ishikawa A, Seki M, et al. (2006) The FOX hunting system: An alternative gain-of-function gene hunting technique. Plant J 48: 974-985

Jiménez VM (2001) Regulation of in vitro somatic embryogenesis with emphasis on the role of endogenous hormones. Rev Bras Fisiol Vegetal 13: 196-223

Kim MJ, Kim JK, Kim HJ, Pak JH, Lee JH, Kim DH, Choi HK, Jung HW, Lee J-D, Chung Y-S, et al. (2012) Genetic modification of the soybean to enhance the $\beta$-carotene content through seedspecific expression. PLoS One 7: e48287

Meurer CA, Dinkins RD, Collins GB (1998) Factors affecting soybean cotyledonary node transformation. Plant Cell Rep 18: $180-186$

Murashige T, Skoog F (1962) A revised medium for rapid growth and bio assays with tobacco tissue cultures. Physiol Plant 15: 473-497

Ortiz-Ospina E, Beltekian D, Roser M (2019) Trade and globalization. Published online at OurWorldInData.org. http:// ourworldindata.org/trade-and-globalization

Paz MM, Martinez JC, Kalvig AB, Fonger TM, Wang K (2006) Improved cotyledonary node method using an alternative explant derived from mature seed for efficient Agrobacteriummediated soybean transformation. Plant Cell Rep 25: 206-213

Peeters NM, Chapron A, Girirch A, Grandjean O, Lancelin D, Lhomme T, Vivrel A, Small I (2000) Duplication and quadruplication of Arabidopsis thaliana cyteinyl- and asparaginyl-tRNA synthetase genes of organellar origin. $\mathrm{J} \mathrm{Mol}$ Evol 50: 413-423

Song Z, Tian J, Fu W, Li L, Lu L, Zhou L, Shan Z, Tang G, Shou H (2013) Screening chinese soybean genotypes for Agrobacteriummediated genetic transformation suitability. Jzus 14: 289-298

Wu XR, Kenzior A, Willmot D, Scanion S, Chen Z, Topin A, He SH, Acevedo A, Folk WR (2007) Altered expression of plant lysyl tRNA synthetase promotes tRNA misacylation and translational recording of lysine. Plant J 50: 627-636

Yano T, Tanaka H, Kurino T, Yamamoto A, Kunitake H, Saeki Y, Akashi R (2014) Functional genetic analysis of Arabidopsis thaliana SYNC1 in Lotus corniculatus super-growing roots using the FOX gene-hunting system. Plant Root 9: 6-14 